\title{
The effect of Huanghe River runoff on the occurrence, transportation and speciation of mercury in the Huanghe Estuary and adjacent sea
}

\author{
Lu Xiankun, Yang Min, Shi Jiande and Feng Xiaoju \\ Department of Marine Chemistry, Ocean University of Qingdao, P.R. China
}

(Received January 31, 1990; Accepted September 5, 1990)

\begin{abstract}
Mercury content of the sediments and water in the area of the Huanghe Estuary and adjacent sea was measured for several species. The content values were found to be among the lowest levels in the world estuaries. The distributions, more or less homogeneous in dry season while exhibiting a gradient during the flood season, show the main role of the Huanghe runoff, having a heavy load of silt. Also observed were the transformation of inorganic mercury into organic species during the mixing between fresh and saline waters, rectilinear correlation of sediment mercury to its median diameter, and the stratification of mercury species at the near estuary.
\end{abstract}

Mercury is a well-known toxic metal which, being an industrial waste, reaches estuaries in great amounts. Acting as suspended particles of river water deposited in estuaries, mercury is accumulated and concentrated in sediments. In addition, due to the methylation and transportation in the food chain, mercury will finally endanger human beings. Presently, it has been announced that the estuaries of some industrialized countries contain an abnormally high content of mercury (Figueres et al., 1985; Föstner and Wittman, 1981). Also, mercury has a very strong affinity to organic functional groups containing sulfur, nitrogen, or oxygen and is well-known as a "particulate active" element. Consequently, the biogeochemical behavior of mercury in a water column has special characteristics. The study of this behavior for a particular estuary can provide not only information on mercury contamination assessment and prediction but also an insight into the transfer mechanism of mercury species, the result of the transportation of mercury, and the circulation of mercury in the hydrosphere. Several authors have reported on the content of mercury and its transformation for the Changjang Estuary, Bohai Bay, and East
China Sea (Xu et al., 1982; Zheng and Zhang, 1985; and Zhang, 1980). The Huanghe Estuary is an important area in China and is well-known for its very heavy load of suspended particulate matter which renders a significant influence on the southern Bohai and Huanghai Seas. In order to obtain information on the contamination and transportation of mercury, this paper presents the primary results of mercury species in a water column, sediments, and suspended particles based on a survey of the Huanghe Estuary and the adjacent sea during the period of 1983-1985.

\section{EXPERIMENTAL}

\section{Sampling}

Figure 1 shows the location of the sampling stations. The sampling area is located between $37^{\circ} 30^{\prime}-38^{\circ} 30^{\prime} \mathrm{N}$ and $119^{\circ}-120^{\circ} \mathrm{E}$. For comparison with the open sea, two stations (\#24 and 25) located on the boundary between the Bohai and Huanghai Seas were selected. The samples of surface sediment were taken during November to December 1983 with use of a grab sampler. The central part of each sediment sample was collected in a plastic bag using a plastic 


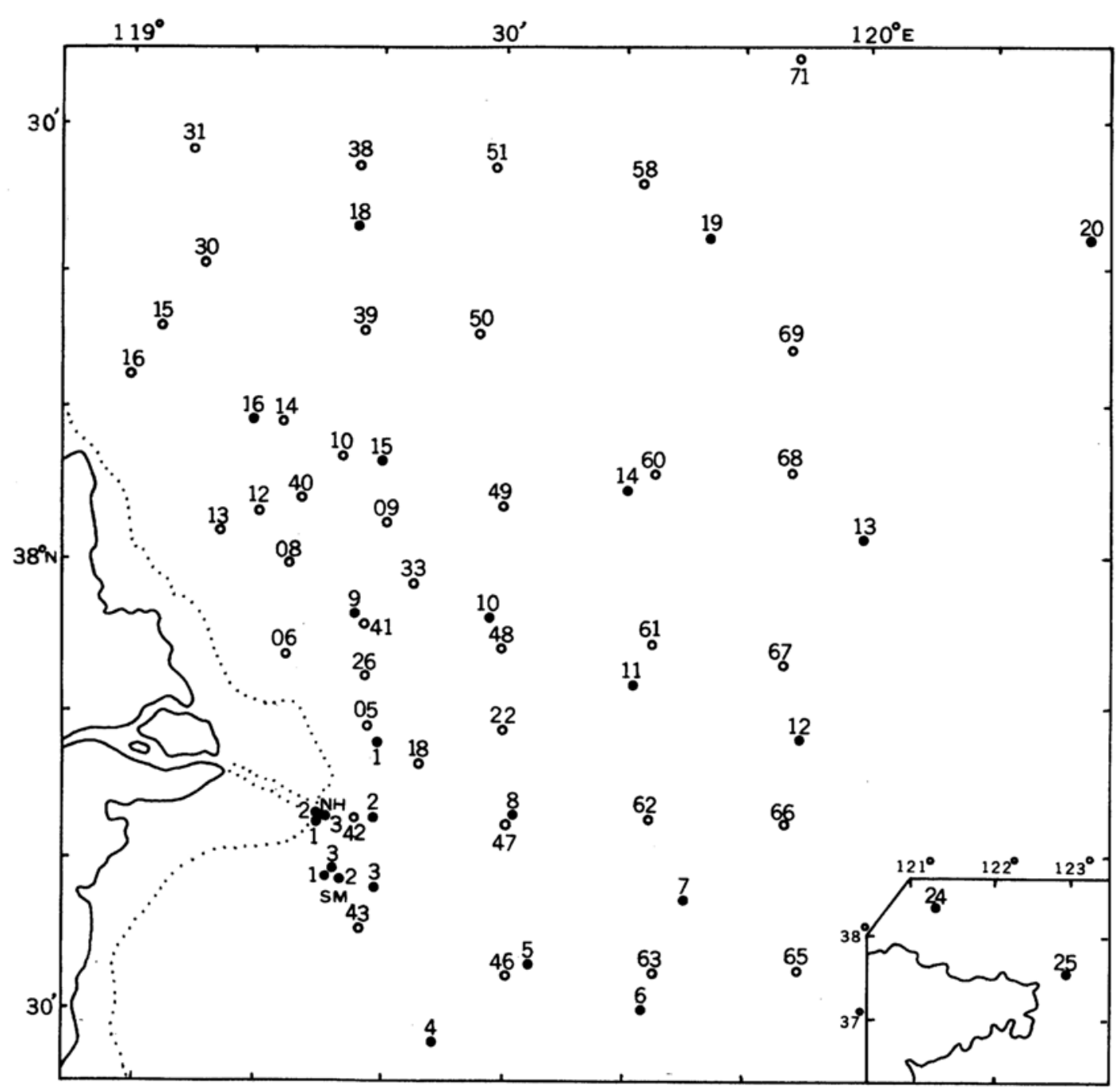

Fig. 1. Map of the Huanghe Estuary and adjacent sea showing the sampling stations for sediments (O) and water $(\bullet)$.

spatula and immediately frozen. Using a gravity sampler, several core samples were collected along the section between the river mouth and the Bohai Sea. The water samples were taken during May and August of 1985 with use of Niskin samplers on board the RV Dong-Fang-Hong, while samples from stations NH1 to 3 and SM1 to 3 were obtained with a plastic bucket using a small boat. All the samplers were precleaned by soaking in nitric acid and rinsed in distilled water. After the samplers were removed from the water column onto a frame, subsamples were immediately gathered in glass bottles precleaned with a solution containing $\mathrm{HNO}_{3}, \mathrm{KMnO}_{4}$, and $\mathrm{K}_{2} \mathrm{~S}_{2} \mathrm{O}_{8}$. A number of samples were passed through a $1 \mu \mathrm{m}$ glass fiber filter (Whatman GF/C) to collect suspended particles and the solution filtered for a determination of dissolved species. The filters used were precleaned by baking overnight at temperature of $500^{\circ} \mathrm{C}$.

\section{Analysis}

Inorganic mercury content in the $150 \mathrm{ml}$ filtered water was determined on board using two stage gold amalgamation coupled with cold vaper atomic absorption spectrometer (CVAAS) 
described by Grasshoff et al., (1983) and Lu et al., (1986). After digestion by $\mathrm{HNO}_{3}, \mathrm{KMnO}_{4}$, and $\mathrm{K}_{2} \mathrm{~S}_{2} \mathrm{O}_{8}$, the mercury content determined in the filtered water is termed total dissolved mercury while that in the unfiltered water is called total mercury. The total mercury content in the particulate and sediments was determined using CVAAS combining the digestion by $\mathrm{HNO}_{3}$, $\mathrm{KMnO}_{4}$, and $\mathrm{K}_{2} \mathrm{~S}_{2} \mathrm{O}_{8}$ (Lu et al., 1986).

\section{Results AND Discussion}

Total mercury in the sediments

Table 1 lists the mercury content of the surface sediments from the Huanghe Estuary and adjacent sea, while the distribution is shown in Fig. 2. The mercury content of the sediments ranges from 0.01 to $0.03 \mu \mathrm{g} / \mathrm{g}$, with an average of $0.0198 \pm 0.0045 \mu \mathrm{g} / \mathrm{g}$. As shown in Table 2,
Table 1. Values of mercury content of surface sediments at stations in the Huanghe Estuary and adjacent sea $(\mu \mathrm{g} / \mathrm{g})$

\begin{tabular}{cccccc}
\hline Stn. & Content & Stn. & Content & Stn. & Content \\
\hline 05 & 0.025 & 31 & 0.016 & 51 & 0.017 \\
06 & 0.020 & 33 & 0.026 & 58 & 0.019 \\
08 & 0.022 & 38 & 0.028 & 60 & 0.018 \\
09 & 0.023 & 39 & 0.018 & 61 & 0.016 \\
10 & 0.020 & 40 & 0.024 & 62 & 0.014 \\
12 & 0.019 & 41 & 0.018 & 63 & 0.017 \\
13 & 0.019 & 42 & 0.023 & 65 & 0.012 \\
14 & 0.024 & 43 & 0.026 & 66 & 0.015 \\
15 & 0.023 & 46 & 0.023 & 67 & 0.012 \\
16 & 0.022 & 47 & 0.013 & 68 & 0.011 \\
18 & 0.024 & 48 & 0.025 & 69 & 0.016 \\
22 & 0.025 & 49 & 0.019 & 71 & 0.016 \\
30 & 0.024 & 50 & 0.020 & & \\
\hline
\end{tabular}

the value is far lower than the mercury content reported of rivers, estuaries, and coastal seas from around the world, and also being close to

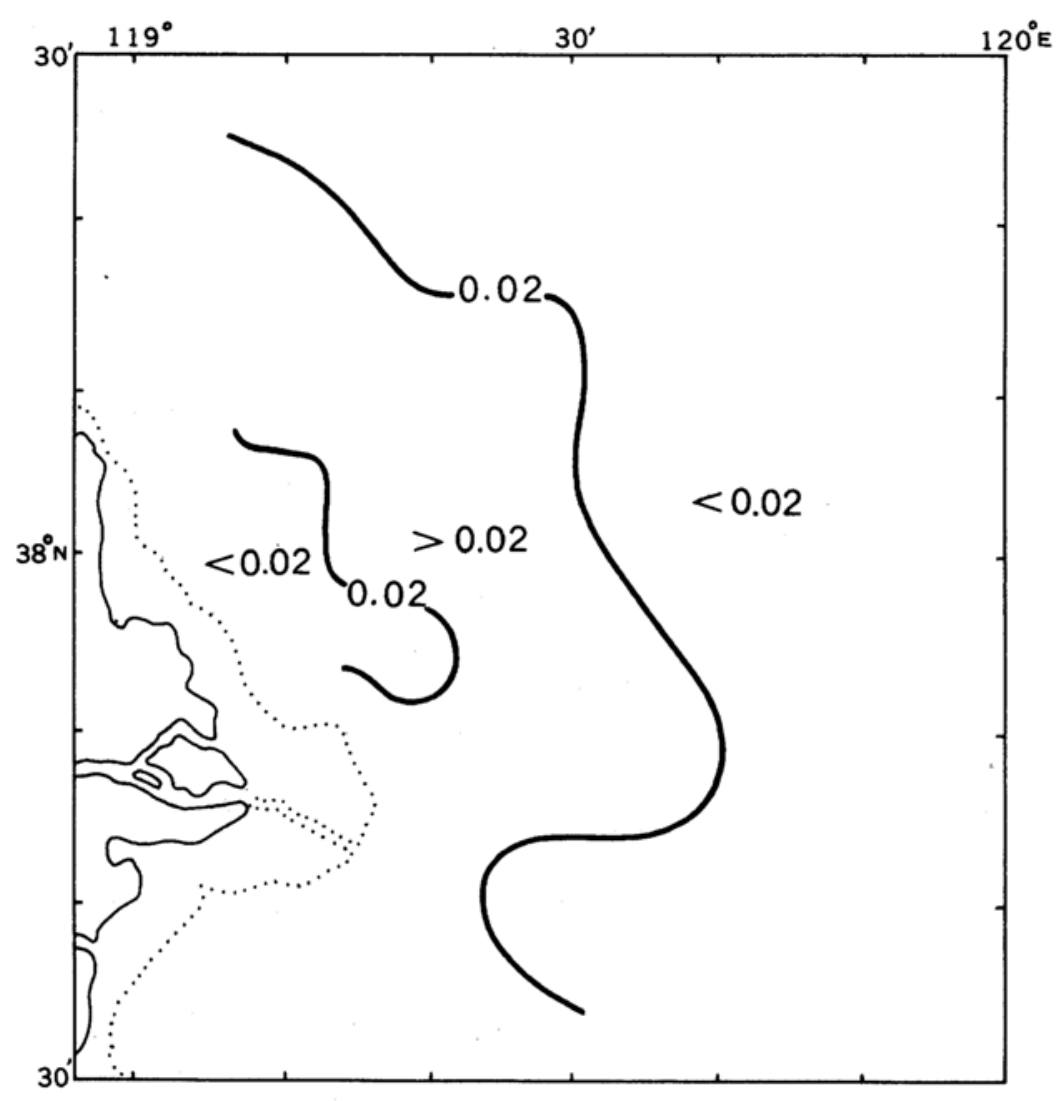

Fig. 2. Distribution of mercury $(\mu \mathrm{g} / \mathrm{g}$ ) found in sediments in the Huanghe Estuary. 
Table 2. Average of mercury content in sediments from River Estuaries, and seas world-wide and the average found in rocks $(\mu \mathrm{g} / \mathrm{g})$

\begin{tabular}{lcl}
\hline Area & Content & References \\
\hline Granitic & 0.13 & [Föstner and Müller, \\
& 0.3 & [974] \\
["] \\
Shales & 0.02 & ["] \\
Sandstone & 0.02 & ["] \\
Huanghe Estuary & 0.03 & [Nelson et al., 1975] \\
Bering Sea & 0.048 & [Xu et al., 1982] \\
Changjang Est. & $0.011-0.093$ & ["] \\
Changjang Est. & 0.13 & [Smith et al., 1973] \\
Thames Est. & 0.33 & [Lindberg et al., 1975] \\
Mississippi Est. & 0.29 & ["] ] \\
San Francisco Est. & 0.35 & [Loring, 1975] \\
St. Lawrence Gulf & 6.9 & [Lindberg et al., 1975] \\
Rhine Est. & 2.5 & [Zomgde and Desai, \\
Bombay R. & & 1981] \\
& 30 & [Kumagai and \\
Minamata Bay & & Nishimura, 1978] \\
\hline
\end{tabular}

${ }^{*}$ This paper.

the mercury content found in average sandstone. Such low mercury content suggests that the area investigated has so far not been contaminated by anthropogenic mercury. The mercury content of plateau loess from west China, measured simultaneously, ranged between 0.007 and 0.010 $\mu \mathrm{g} / \mathrm{g}$. Huanghe River sediments in the area of Kenli County showed mercury content values of $0.012 \mu \mathrm{g} / \mathrm{g}$. The similar content of mercury among loess, river sediments, and estuarine sediments is another piece of evidence that the estuarine sediments are derived mainly from the weathering of plateau loess and sediments along the Huanghe River valley. This conclusion is further demonstrated by the tongue-like distribution of the mercury content in sediments of the Estuary (see Fig. 2), which indicates the movement of river silt, i.e. towards the northeast (Huang et al., 1985). This pattern of mercury distribution in sediments coincides with that of the distribution of the tidal flat and the northwest annual residual current (Liu et al., 1985; Lu et al., 1985).

This character of the distribution is related to the granular size of the sediments. Figure 3 illustrates a linear relationship between the mer-

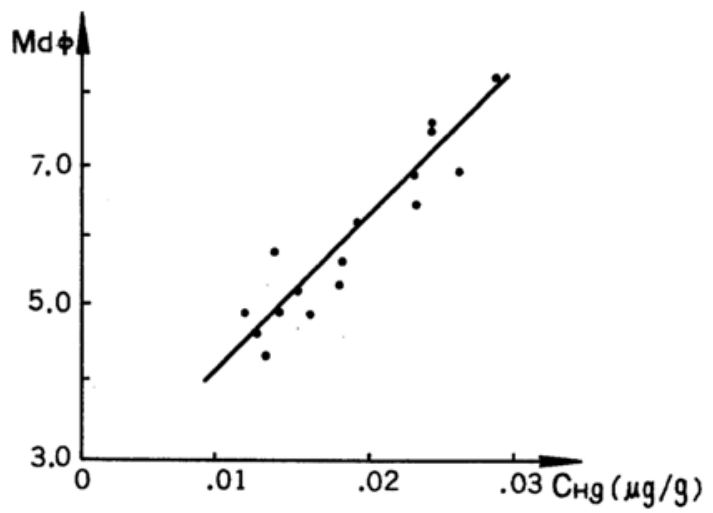

Fig. 3. Scatter diagram of sediment mercury $(\mu g / g)$ vs median diameter $\left(M d_{\phi}\right)$.

cury content of sediments and the values of grain size distribution $\left(\mathrm{Md}_{\phi}\right)$. The regression formula can be approximated as

$$
\mathrm{C}_{\mathrm{Hg}}=0.0042 \times \mathrm{Md}_{\phi}-0.0061, \quad(n=16),
$$

with a very good correlation coefficient $(r=0.95)$. The regression formula is similar to that pointed out by Zhang (1980) for the sea area adjacent to northern Jiangsu. The phenomenon that the grain content decreases close to the open sea is quite similar to that found in many of the estuaries around the world. This results from geochemical and biological interactions between the river and the sea. de Groot et al. (1971) reported that the gradient in the distribution of trace metals in the Rhine Estuary was caused by the decomposition of organic matter during the mixing of river water with seawater, thereby removing the trace metals from the solid phase into the water. To explain the gradient distribution of heavy metals in the Elbe Estuary, Förstner and Müller (1974) concluded that the reason for the gradient was the mixing between sediments of the Elbe River and those of the North Sea.

The cases described above for the Rhine and Elbe Estuaries do not appear to play a significant role in the Huanghe Estuary. The silt in the Huanghe River has a distinct inorganic character, so that the decomposition of organic matter is not important. The silt load of the Huanghe River is so heavy that the mixing of sea 


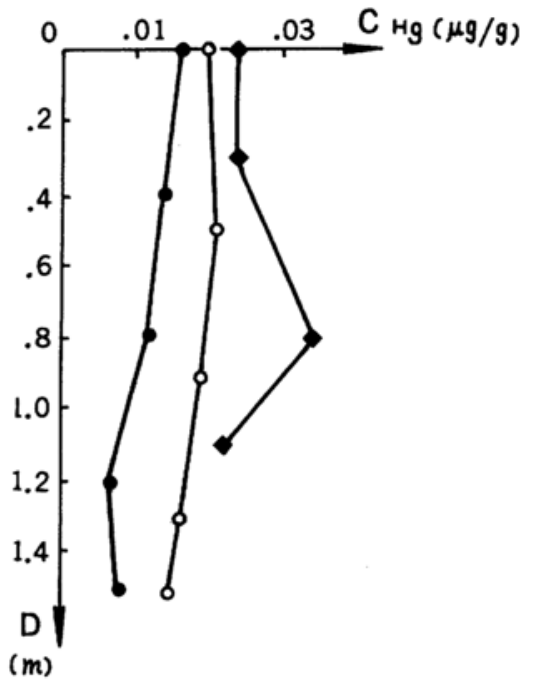

Fig. 4. Vertical profiles of sediment mercury at Stations $40(\bullet), 50(0), 71(\bullet)$.

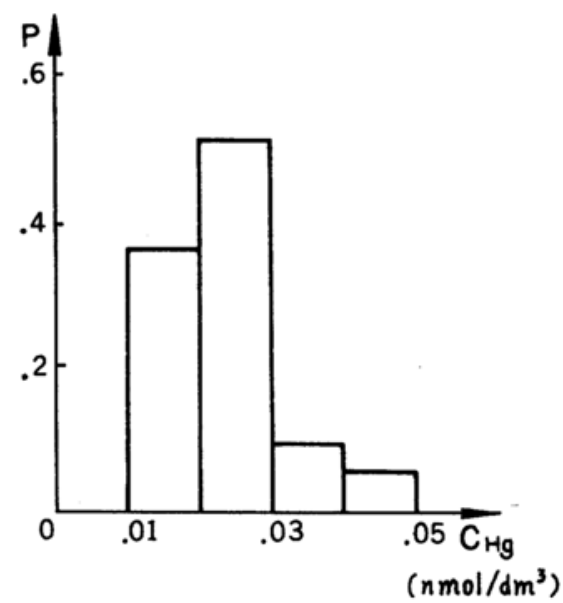

Fig. 5. Histogram of total dissolved mercury $\left(\mathrm{nmol} / \mathrm{dm}^{3}\right)$.

sediment would also not be very substantial. Meade (1969) pointed out that, owing to the bottom current flow toward the coast (the salt wedge), sediment from the far estuary would be continuously moved toward the coast along the floor, i.e. the so-called resuspension. The transportation of sediment by resuspension can be very dominant in the Huanghe Estuary, considering the relationship between mercury content and granular sizes, the residual annual current toward the northwest, the salt wedge ob- served in the present investigation, and the shallow floor with strongly seasonal wind. This resuspension towards the coastal regions is probably an important reason for sediment size to be larger towards the sea and smaller towards the coast, thus forming an area of high mercury-content sediments with small granular size in the Estuary.

The vertical profiles of the mercury content of sediments from three stations (see Fig. 4) suggest that there is a trend for mercury to decrease with depth. This fact implies a release of mercury from sediment to pore water and then into overlying water during diagenesis. However, this process is not only very slow but also very small quantitatively, and therefore cannot have any significant influence on the mercury concentration in the water column. At Station 40 a high mercury content is found at the middle depth $(0.8 \mathrm{~m})$, which is similar to the distribution pattern of other metals (Huang et al., 1985). Station 40 is in the area of the past Huanghe Estuary, and thus may reflect the character of that sedimentation.

\section{Total dissolved mercury}

The results from the August, 1985 investigation suggest that the total dissolved mercury in the water column ranged from 0.010 to 0.030 $\mathrm{nmol} / \mathrm{dm}^{3}$, with no significant spatial gradients or periodic variations. Figure 5 presents a histogram of the total dissolved mercury, from which it can be seen that the most frequent value falls between $0.02-0.03 \mathrm{nmol} / \mathrm{dm}^{3}$. When unreasonable values are deleted, the spatial average of the total dissolved mercury over stations 4 through 25 is $0.022 \pm 0.006 \mathrm{nmol} / \mathrm{dm}^{3}$. On the other hand, the average of the time series results at Station 2 is $0.025 \pm 0.008 \mathrm{nmol} / \mathrm{dm}^{3}$, close to the value of the spatial average. Of the two cases, the former can be regarded as a typical value of mercury in the far estuary and sea area while the latter resembles values from the near estuary and the area significantly influenced by river water. The total dissolved mercury displays a characteristic of stability and homogeneity-implying that, during the mixing 


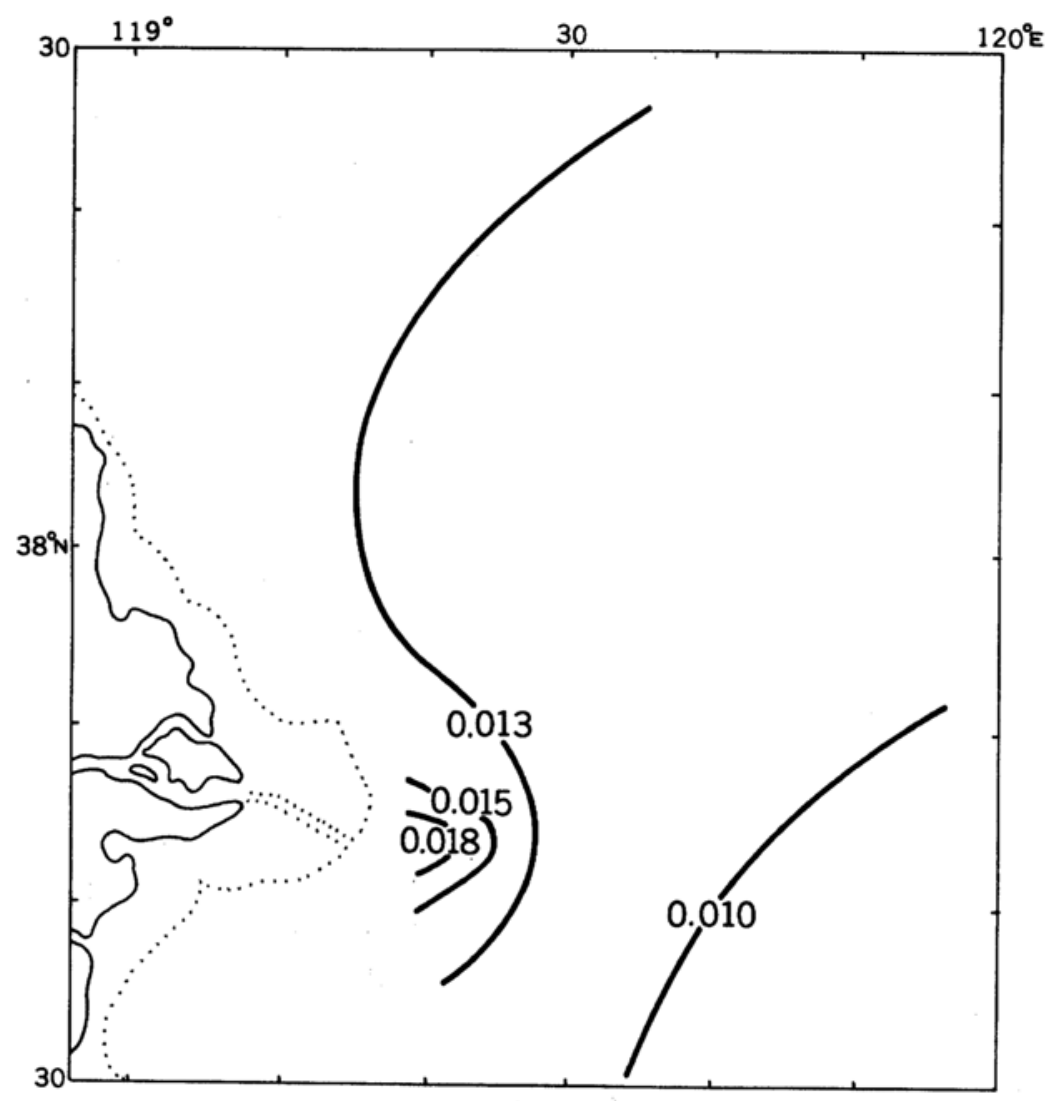

Fig. 6. Distribution of inorganic mercury $\left(\mathrm{nmol} / \mathrm{dm}^{3}\right)$ in the Huanghe Estuary.

of fresh water with seawater, there is no significant release of mercury into the water from the suspended particles carried by the Huanghe River. This can be interpreted in two ways; either there is near equilibrium between adsorption and desorption of particulates for mercury or the reaction between the heterogeneous phases is very slow so that no significant variation in the water column can be measured. The level of the total dissolved mercury in the Huanghe Estuary and adjacent sea is comparable with that of recently available measurements in the open sea and unpolluted estuaries (Lu et al., 1986; Olafsson, 1983; Slemr et al., 1981), proving that the area of the present study is still in a natural state-not affected by anthropogenic mercury.

\section{Inorganic mercury}

The content of inorganic mercury measured in water columns during May and August of 1985 ranged from 0.005 to $0.023 \mathrm{nmol} / \mathrm{dm}^{3}$ and from 0.004 to $0.026 \mathrm{nmol} / \mathrm{dm}^{3}$, respectively. These values averaged $0.010 \pm 0.004 \mathrm{nmol} / \mathrm{dm}^{3}$ (May, $\mathrm{n}=76$ ), and $0.014 \pm 0.006 \mathrm{nmol} / \mathrm{dm}^{3}$ (August, $n=70$ ), displaying no significant seasonal variation. During the dry season, the spatial distribution of inorganic mercury in the Estuary and adjacent sea did not exhibit any gradient, which may be related to the small runoff and suspended load of the Huanghe River for that period. During the flood season, a slight gradient of inorganic mercury can be found (see Fig. 6). In the near estuary, a slightly higher mercury content implies the influence of the Huanghe River water $\left(0.019 \pm 0.006 \mathrm{nmol} / \mathrm{dm}^{3}\right.$ at Station 2 represents a 25 -hour mean) while in the far estuary and sea area, lower values of mercury content are obtained (the mean value for Stations $4-25$ is $0.0097 \pm 0.0026 \mathrm{nmol} / \mathrm{dm}^{3}$ ) with 


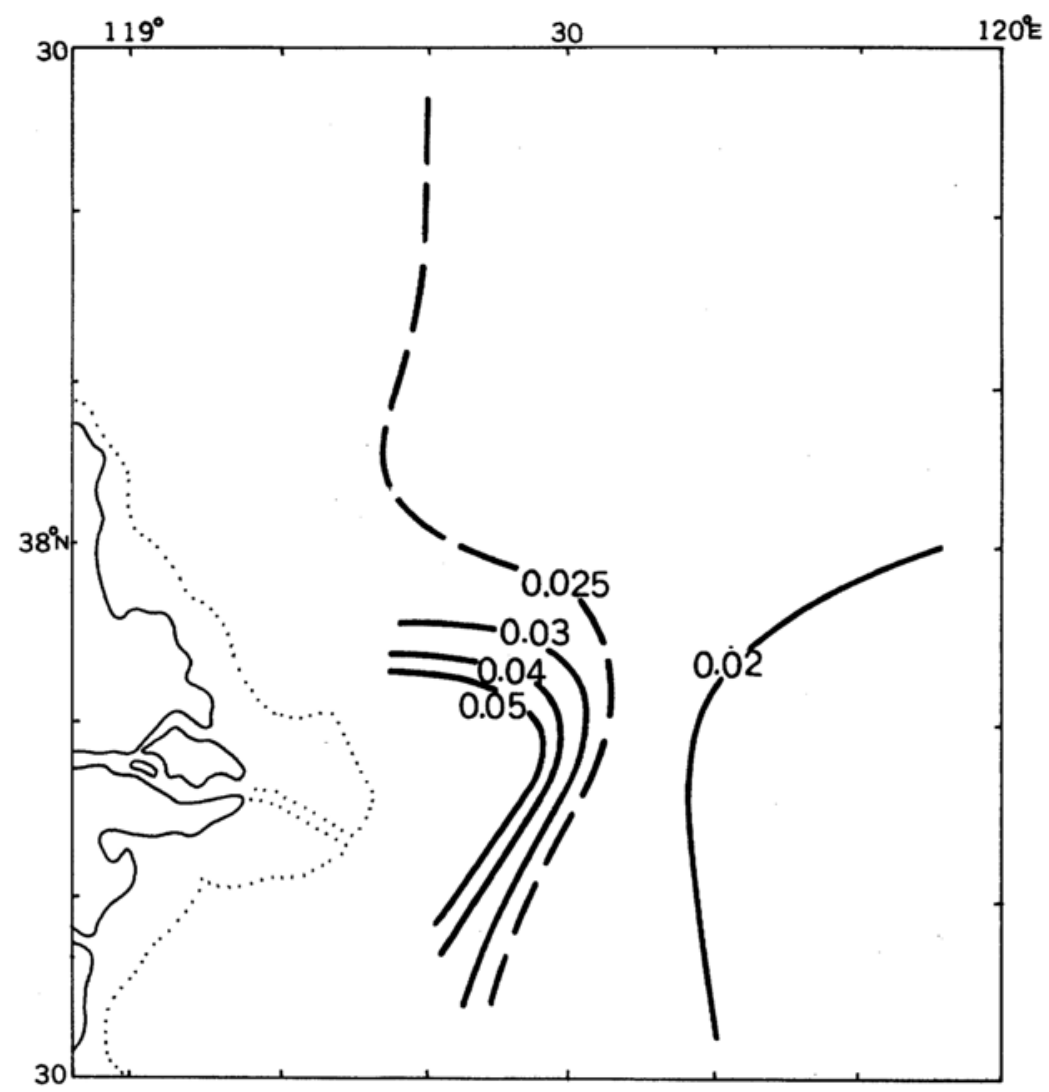

Fig. 7. Distribution of total mercury $\left(\mathrm{nmol} / \mathrm{dm}^{3}\right)$ in the Huanghe Estuary.

the lowest value at the open sea (less than 0.010 $\mathrm{nmol} / \mathrm{dm}^{3}$ ).

Inorganic mercury makes up a large proportion of the total dissolved mercury, especially in the near estuary. For example, an average of $73 \%$ of the total dissolved mercury at Station 2 is due to the inorganic species. Such a high inorganic proportion is quite different from most estuaries world-wide (Zhou et al., 1980; Figueres et al., 1985). However, it is consistent with the inorganic character of the Huanghe River: low production, low dissolved organic matter, and a high content of silt. Due to the stable and homogeneous distribution of total dissolved mercury, the gradient distribution of the inorganic species suggests that a part of the inorganic mercury will be transformed into organic species during the mixing of river water with seawater.
The total mercury in a given water column under investigation is closely related to the content of suspended matter in the water. During May of 1985, a month having small runoff, with low and homogeneous content of silt (mostly less than $50 \mathrm{mg} / \mathrm{dm}^{3}$ ), the content of total mercury was relatively homogeneous. The content averaged $0.034 \pm 0.007 \mathrm{nmol} / \mathrm{dm}^{3}(\mathrm{n}=35)$ and was less than $0.025 \mathrm{nmol} / \mathrm{dm}^{3}$ in the area of high salinity, northeast of the estuary, being close to the content of total dissolved mercury. Due to large runoff and a large variation of suspended particles in the investigated area during August, the total mercury content showed a large range of variation $\left(0.011-7.0 \mathrm{nmol} / \mathrm{dm}^{3}\right)$. In the far estuary and sea area, however, it remained stabilized at $0.023 \pm 0.005 \mathrm{nmol} / \mathrm{dm}^{3}$ (averaged over Stations 4-25).

The total mercury and particulate mercury have similar gradient distributions in the flood 


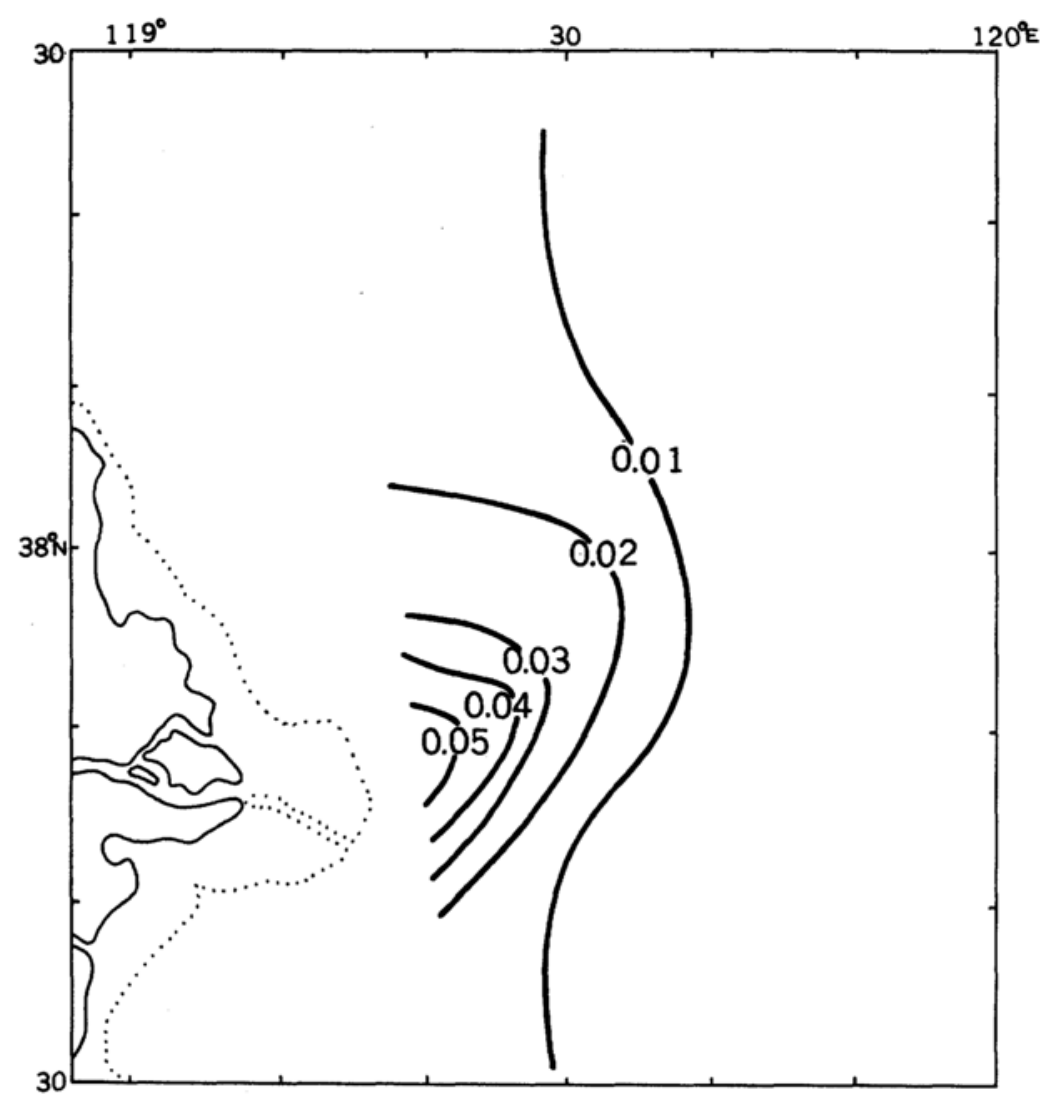

Fig. 8. Distribution of particulate mercury $\left(\mathrm{nmol} / \mathrm{dm}^{3}\right)$ in the Huanghe Estuary.

season, i.e. a tongue-shaped isoline stretching from the river mouth toward the northeast (see Figs. 7, 8), which is consistent with the distribution of salinity and particulate content (Figs. 9, 10). This consistency implies that particulate mercury plays a dominant role in transporting total mercury in the Huanghe Estuary. On the other hand, it also suggests that the mixing process still remarkably influences the distribution pattern of total and particulate mercury, although the sedimentation plays an important role in the estuary. Therefore, the distribution pattern of total and particulate mercury, like salinity, can also indicate the direction of silt movement and the mixing of water masses.

Figure 11 shows the distribution of particulate mercury content in solid particles $(\mu \mathrm{g} / \mathrm{g})$. Compared with Fig. 8, it has a reverse gradient, i.e. high mercury content in solid particles occurs in the far estuary and sea area (the values can reach $0.8 \mu \mathrm{g} / \mathrm{g}$ ) and low values of content are found in the near estuary $(0.05-0.07 \mu \mathrm{g} / \mathrm{g})$, close to the value for the Huanghe River $(0.054$ $\mu \mathrm{g} / \mathrm{g}$ at Lijing County). This distribution reveals the difference in the properties of particulate mercury between the Huanghe River water and seawater. Plotting the particulate mercury content, $\mathrm{Hg}$ in $\mu \mathrm{g} / \mathrm{g}$, versus suspended matter content, SMC in $\mathrm{mg} / \mathrm{dm}^{3}$, a hyperbolic relationship is found between the two parameters (see Fig. 12). The curve can be fitted by the formula

$$
\mathrm{Hg}=\frac{4.0}{\mathrm{SMC}+4.4}+0.06 \quad(\mathrm{r}=0.95) \text {. }
$$

When SMC is greater than 100 , which occurs in the near estuary, particulate mercury content is relatively stable and is not influenced to any great extent by SMC. The constant value of 0.06 can be taken as the representative mercury content in solid particles found in the Huanghe 


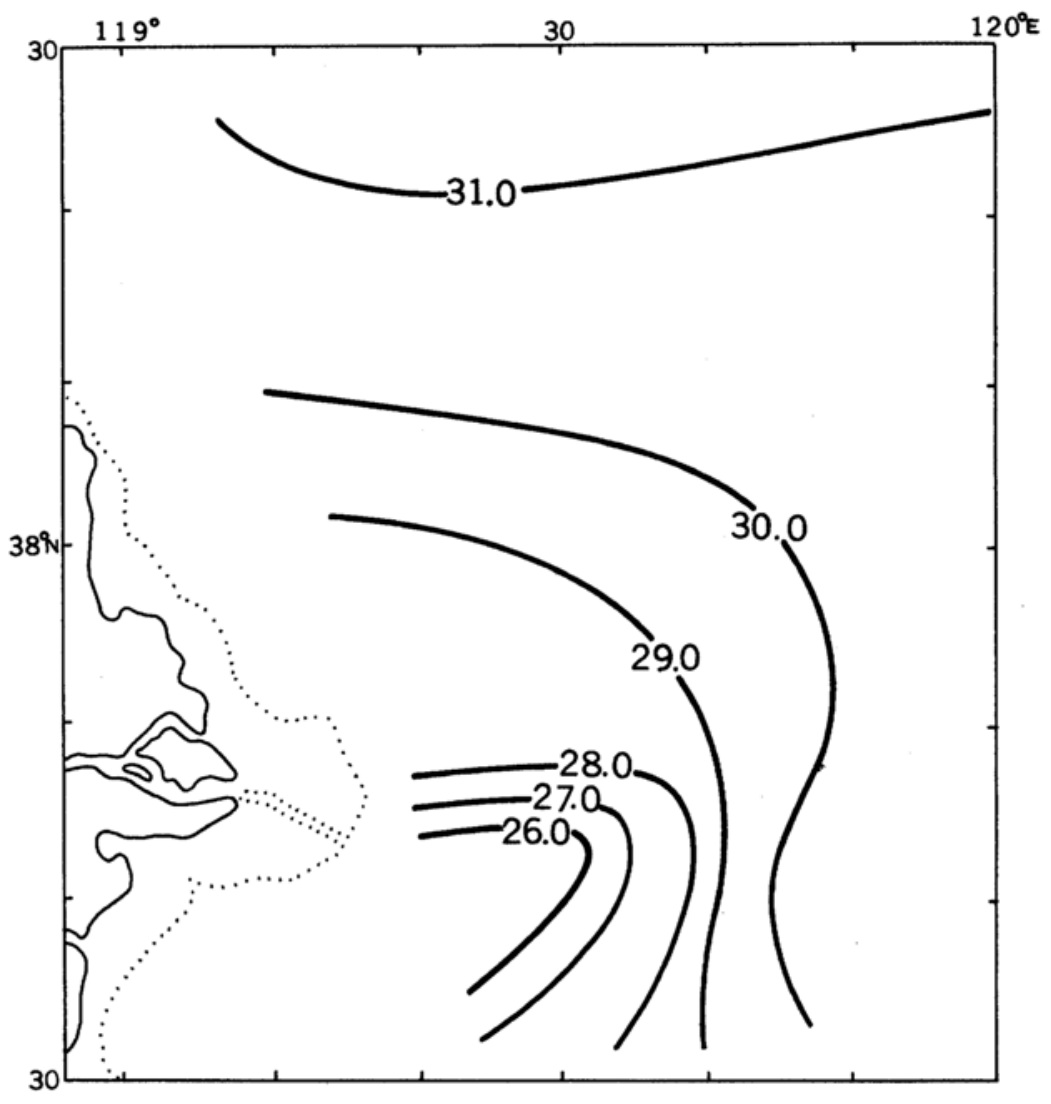

Fig. 9. Distribution of salinity in the Huanghe Estuary.

River water. When SMC is less than $10 \mathrm{mg} / \mathrm{dm}^{3}$, which occurs in the sea area, values of mercury content, $\mathrm{Hg}$, are very high and change rapidly with SMC, showing the nature of the seawater. Cauwet (personal communication) reported a similar relationship between particulate organic carbon (POC) and the suspended matter content, implying that particulate organic matter plays an important role in the particulate mercury content due to a very high affinity to organic matter.

When compared with mercury content in surface sediments, particulate mercury is singificantly higher. This occurs in many rivers and estuaries world-wide (Figueres et al., 1985; Lindberg et al., 1975). In contrast with the conclusion of Figueres et al. (1985) for the Tagus Estuary, it should not be concluded that in the Huanghe Estuary the high mercury content in the particulate compared to that in the surface sediment is an indication of mercury pollution, because the particulate mercury content in the Huanghe Estuary is very low $(0.05-0.8 \mu \mathrm{g} / \mathrm{g})$ when compared with polluted estuaries (particulate mercury $5-32 \mu \mathrm{g} / \mathrm{g}$ ) and also the high content is mainly situated in the far estuary and the adjacent sea area.

\section{Diurnal variation of mercury species}

The 25 hours of continuous observations at Station 2 for two depths were conducted during August, 1985. Using the salinity data, a large difference between the surface and the bottom measurements can be seen (Fig. 13). Lower values of salinity at the surface which widely and irregularly vary display the significant influence of fresh water during most of the measurement time. In contrast, higher salinity occurs in the bottom layer with a small and regular semidiurnal tidal variation. This stratification manifests 


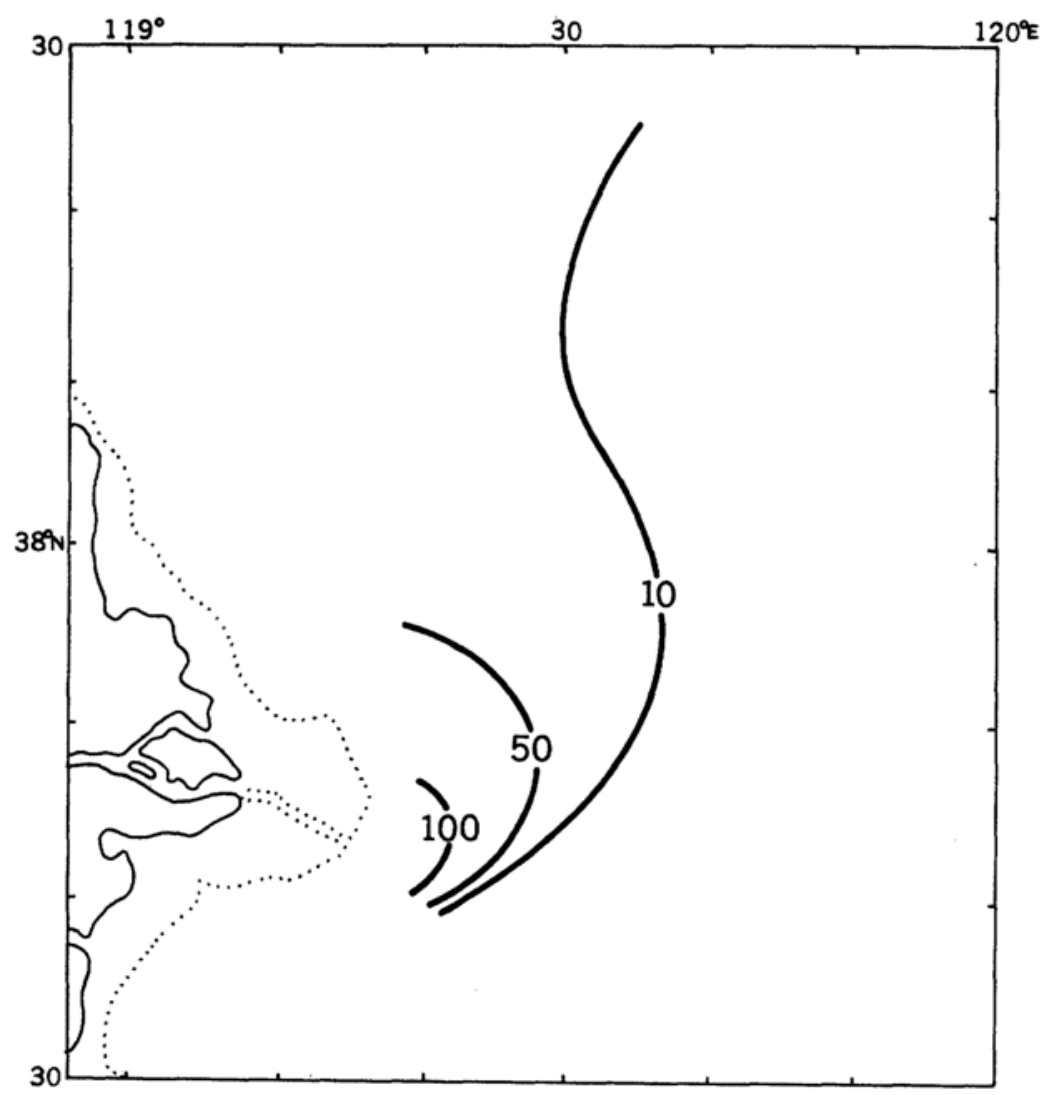

Fig. 10. Distribution of particulate content $\left(\mathrm{mg} / \mathrm{dm}^{3}\right)$ in the Huanghe Estuary.

itself in the form of a salt-wedge type estuary.

The diurnal distribution of suspended matter, total mercury, and particulate mercury, also display a stratification similar to the salinity (Figs. 14 and 15). In the surface water, the content values of these three parameters are generally quite low and display complicated variations. In the bottom layer, higher values of content for these parameters are found and are negatively correlated with salinity. The fact that there are consistent variations of the total mercury, particulate mercury, and suspended matter, along with small diurnal variations of inorganic mercury additionally suggests the importance of particulate mercury in the near estuary.

Figure 16 shows the diurnal variation of mercury content found in solid particulates $(\mu \mathrm{g} / \mathrm{g})$. In the bottom layer, most values of mercury content are less than $0.1 \mu \mathrm{g} / \mathrm{g}$ and are relatively stable, reflecting the dominant role of silt in the
Huanghe River. In the surface layer, the values of mercury content in solid particulates change remarkably and exhibit a trend opposite to that of the suspended matter content (SMC). This reveals that particles in the surface layer are influenced by particles from both river water and seawater.

\section{SUMMARY}

1. The content of all mercury species measured in the Huanghe Estuary and the adjacent sea area exhibits very low values, with sediment mercury ranging between $0.01-0.03 \mu \mathrm{g} / \mathrm{g}$, total dissolved mercury between 0.011-0.029 $\mathrm{nmol} / \mathrm{dm}^{3}$, inorganic mercury in water having values from 0.004 to $0.026 \mathrm{nmol} / \mathrm{dm}^{3}$, and particulate mercury between $0.05-0.81 \mu \mathrm{g} / \mathrm{g}$. All measured values of mercury content are lower than those reported for polluted estuaries world- 


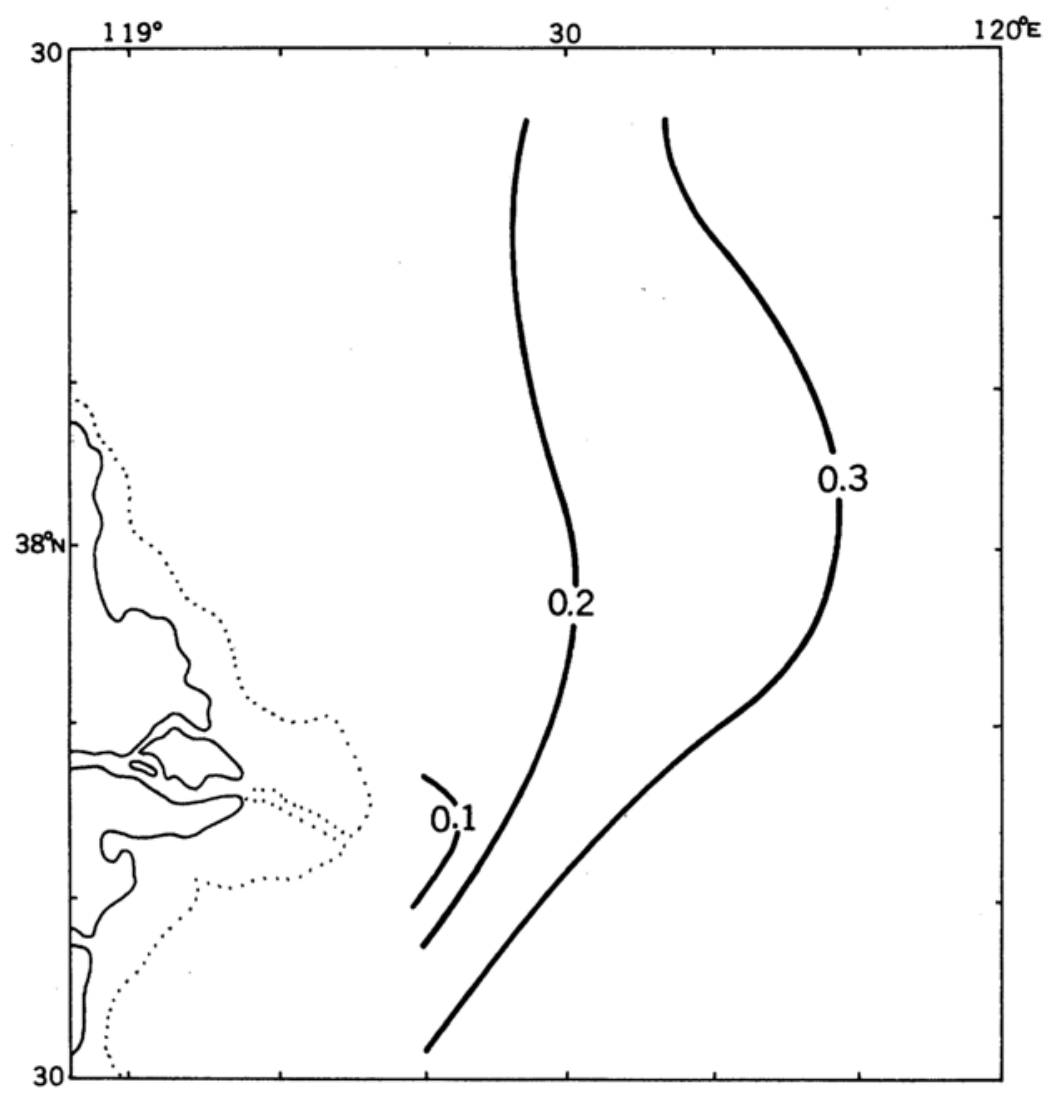

Fig. 11. Distribution of particulate mercury content $(\mu \mathrm{g} / \mathrm{g})$ in the Huanghe Estuary.

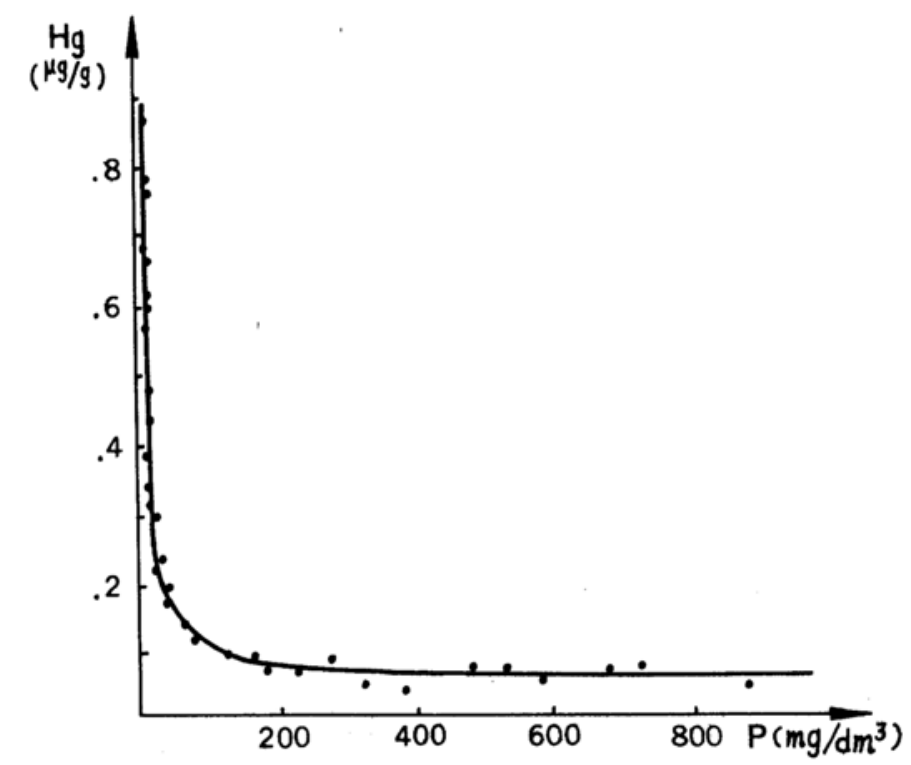

Fig. 12. Fitted curve for particulate mercury $(\mathrm{Hg})$ versus particulate content $(P)$. 


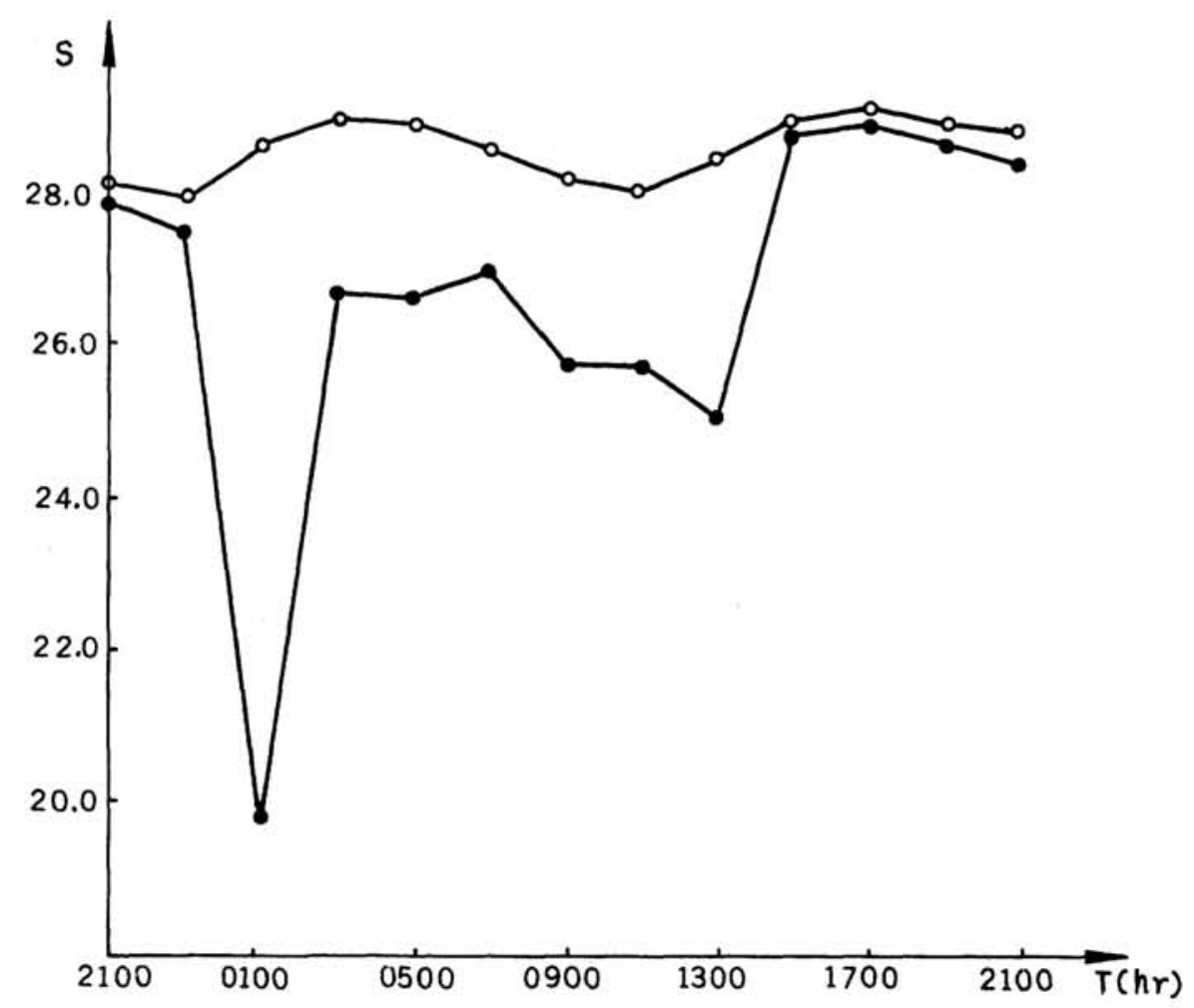

Fig. 13. Diurnal distribution of salinity at Station 2 at depths of $1 \mathrm{~m}(\bullet)$ and $10 \mathrm{~m}(\mathrm{O})$.

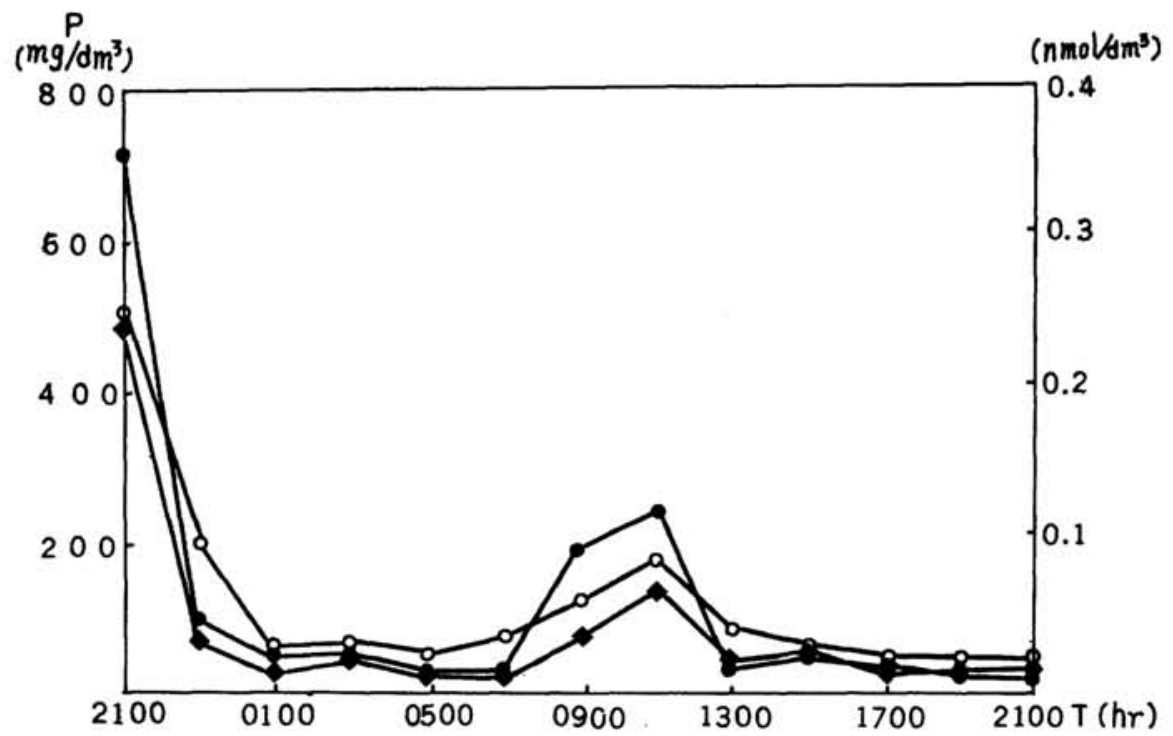

Fig. 14. Diurnal distribution of particulate content ( $\bullet$ ), total mercury $(0)$, and particulate mercury ( $\bullet$ ) at the surface for Station $2(1 \mathrm{~m})$. 


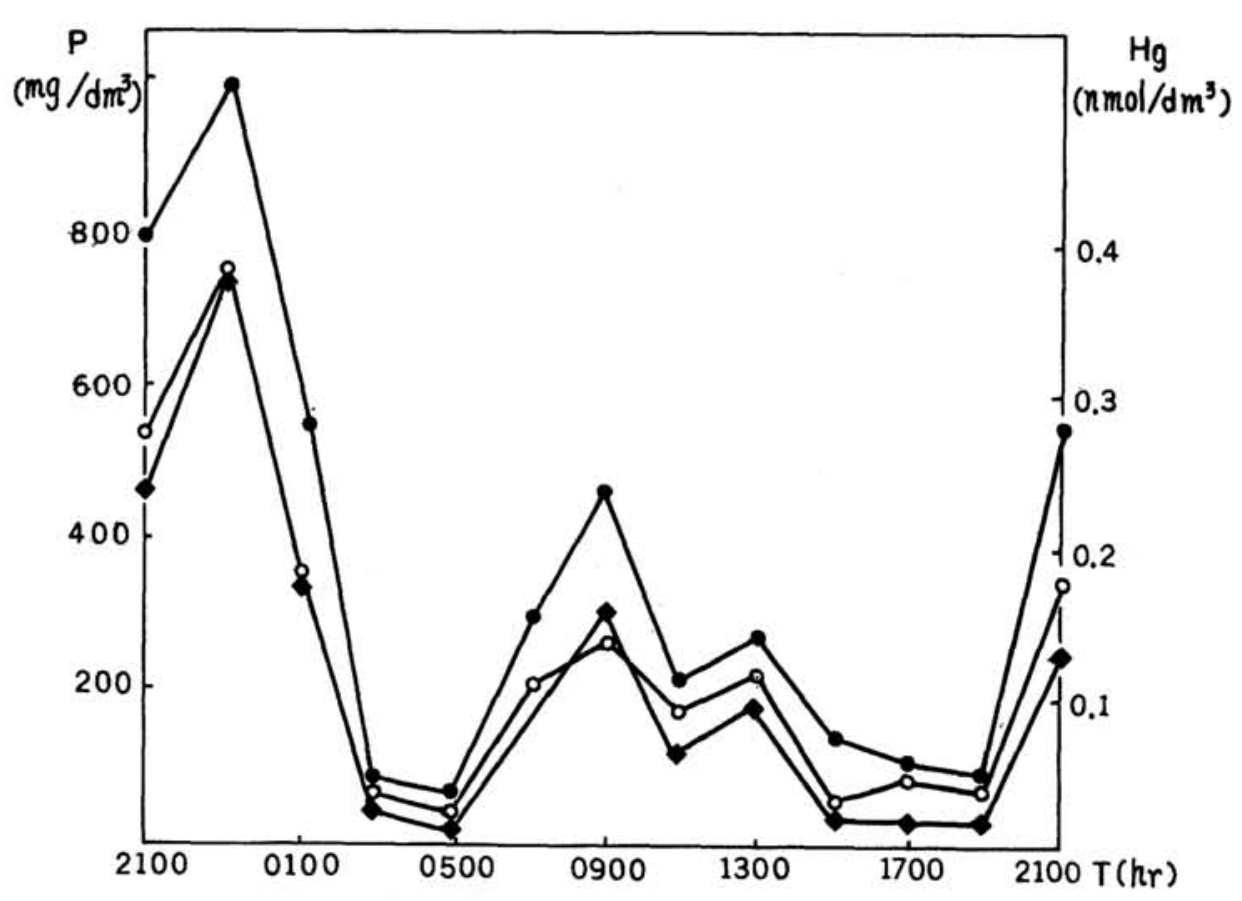

Fig. 15. Diurnal distribution of particulate content ( $\bullet)$, total mercury $(0)$, and particulate mercury (๑) at the bottom of Station $2(10 \mathrm{~m})$.

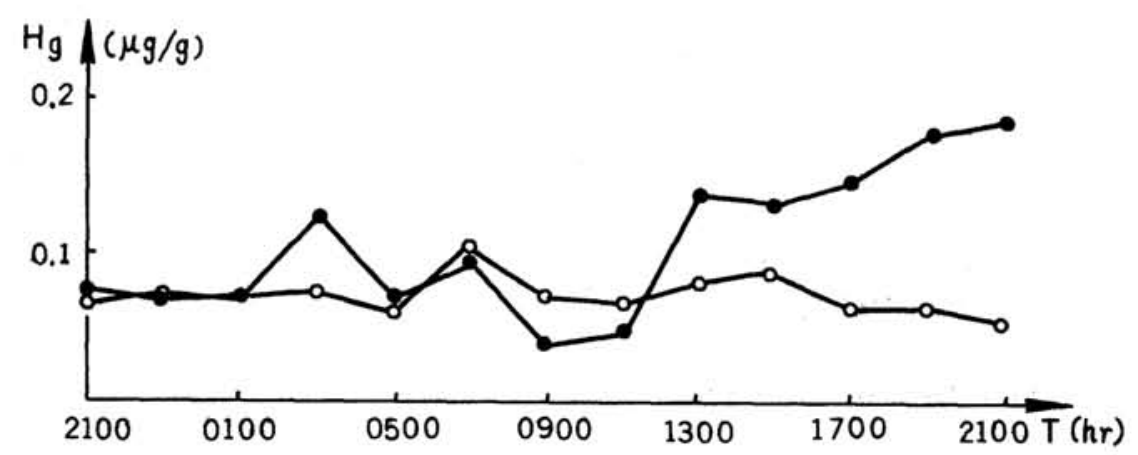

Fig. 16. Diurnal distribution of particulate mercury content $(\mu \mathrm{g} / \mathrm{g})$ at Station 2 for depths of $1 \mathrm{~m}(\bullet)$ and 10 $m(0)$.

wide, which suggests that the Huanghe Estuary has not been contaminated by anthropogenic mercury input.

2. Consistent horizontal gradient distributions of total mercury, particulate mercury, and sediment mercury show the important role of river silt on the distributions of mercury in the estuary. The gradient distributions also reflect the direction of particulate movement.

3. A linear relationship was found between the sediment mercury and its median diameter. A hyperbolic relationship was found between the mercury content in solid particles and the suspended matter content. This relationship demonstrated a difference in particulate properties between the river water and seawater.

4. There was a relatively stable distribution of total dissolved mercury in the estuary and adjacent sea. Inorganic mercury makes up a large proportion of the total dissolved mercury, suggesting the inorganic nature of mercury in the Estuary. The transformation of inorganic mer- 
cury into organic species during the mixing between fresh water and saline water was observed. 5. In the near estuary, the salinity, suspended matter content, and particulate mercury all showed the stratification of a salt wedge. The diurnal variations displayed significant differences between the surface and bottom layers.

\section{REFERENCES}

de Groot, A. J., Goeji, J. J. M. and Zeger, G. (1971) Contents and behavior of mercury as compared with other heavy metals in sediments from river Rhine, am Eins. Geol. Mijnbouw. 50, 293-298.

Figueres, G., Martin, J. M., Meybeek, M. and Seyler (1985) A comparative study of mercury contamination in the Tagus Estuary (Portugal) and major French estuaries (Gironde, Loire, Rhone). Estuarine, Coastal and Shelf Science, 20, 183-203.

Förstner, U. and Müller, G. (1974) Schwermetalle in Flussen und Seen. Berlin, Heidelberg, New York, Springer.

Förstner, U. and Wittman, G. T. W. (1981) Metal pollution in the aquatic environment, Springer pp 191-196.

Grasshoff, K., Ehrhardt, M. and Kremling, K. (1983) Methods of seawater analysis, Verlag Chemie. pp 213-217.

Huang Weiwen, Zhang Jing and Lu Xiankun (1985) Distributive features and pollution assessment of heavy metals in the sediments of the Yellow River Estuary and its relation to the movement of suspended materials. China Journal of Environment Science 6(4), 29-34.

Kumagai, M. and Nishimura, H. (1978) Mercury distribution in seawater in Minamata Bay and the origin of particulate mercury. J. Oceanogr. Soc. Japan 34, 50-56.

Lindberg, S. E., Andren, A. W. and Harris, R. G. (1975) Geochemistry of mercury in the estuarine environment. Estuarine Research I, Chemistry, Biology and the Estuarine System Gronin, L. E., ed. Academic Press, London, pp 64-107.

Liu Zhongheng, Wu Jinxiu and Yu Yongjie (1985) The utilization of grain size material to preliminary analysis of the tidal flat sedimentary environment of the Huanghe River delta. Journal of Shandong College of Oceanology 15(1), 159-168.
Loring, D. H. (1975) Mercury in the sediments of the Gulf of St. Lawrence. Can. J. Earth Sci. 7, 12191237.

Lu, X., Johnson, W. K. and Wong, C. S. (1986) Seasonal replenishment of mercury in a coastal fjord by its intermittent anoxicity. Mar. Poll. Bull. 17(6), 263-267.

Lu Yanan, Lin Zhenghong and Sun Yumei (1985) Discussion on distribution patterns of the mineral and their control factors in the sediment off the Huanghe River Estuary. J. Shandong College of Oceanology 15(1), 179-187.

Meade, R. H. (1969) Landward transport of bottom sediments in estuaries of the Atlantic coastal plain. J. Sediment Petrol. 29, 222-234.

Nelson, H. C. H., Pierce, D. E., Leong, K. W. and Waang, F. F. H. (1975) Mercury distribution in ancient and modern sediment of northeastern Bering Sea. Mar. Geol. 18, 91-104.

Olefsson, J. (1983) Mercury concentration in the North Atlantic in relation to cadmium, aluminium and oceanographic parameters. Trace Metals in Sea Water, Wong, C. S. et al. ed, Plenum Press, pp 475-486.

Slemr, F., Seiler, W. and Schuster, G. (1981) Latitudinal distribution of mercury over the Atlantic Ocean. J. Geophys. Res. 86, 1159-1166.

Smith, J. D., Nicholson, R. A. and Moore, P. J. (1973) Mercury in sediments from the Thames Estuary. Environ. Poll. 4, 153-157.

Xu Kuncan, Huang Shuilong and Wu Liqing (1982) Studies of heavy metals in the estuarine sediments of the Changjiang River. Acta Oceanologica Sinica 4(4), 440-449.

Zhang Shisan (1980) An approach to the estimation of some heavy metals reserved in sediments of the East Sea. China Journal Environment Science 1(4), 3234.

Zheng Shunqin and Zhang Shumei (1985) Mercury in sediments of Bohai Bay. Oceanologia et Limnologia Sinica 6(2), 121-126.

Zhou Jiayi, Qian Wanying and Fu Ruiwen (1980) Marine Geochemistry II: The chemical forms of mercury in seawater and the seawater-sediment mercury interchange. Journal of Shandong College of Oceanology 10(4), 33-41.

Zingde, M. D. and Desai, B. N. (1981) Mercury in Thana Greek, Bombay Harbour. Mar. Poll. Bull. 12, 237-245. 